\title{
Early and long-term results of bilateral internal thoracic artery grafting in dialysis patients
}

\author{
Yasuhiko Kawaguchi $^{1}$, Hideki Kitamura ${ }^{1}$, Kazuya Konakano ${ }^{1}$, Mototsugu Tamaki ${ }^{1}$, and \\ Yasuhide Okawa ${ }^{1}$ \\ ${ }^{1}$ Nagoya Heart Center
}

June 1, 2020

\begin{abstract}
Background: The benefits of bilateral internal thoracic artery (BITA) grafting during coronary artery bypass grafting in dialysisdependent end-stage renal disease patients remain unclear. We compared the early and long-term effectiveness of coronary artery bypass using BITA versus single internal thoracic artery (SITA) grafting in this population. Methods: Eighty-nine consecutive patients with dialysis-dependent end-stage renal disease who underwent isolated coronary artery bypass grafting were retrospectively analyzed. Early and long-term results were reviewed, and univariate and multivariate analyses of risk factors for late death and major adverse cardiac events (MACE) was performed. Results: There was no significant difference between the BITA $(\mathrm{n}=65)$ and SITA $(\mathrm{n}=24)$ groups in in-hospital mortality $(0 \%$ vs. $4.2 \%, \mathrm{p}=0.27)$ and the incidence of deep surgical wound infection $(4.6 \%$ vs. $4.2 \%, \mathrm{p}=1.00)$. The overall survival rate in the BITA and SITA groups were $90.2 \%$ vs. $82.3 \%, 64.6 \%$ vs. $57.6 \%$, and $51.8 \%$ vs. $20.6 \%$ at 1,3 , and 5 years, respectively. Overall survival was comparable but was more favorable in the BITA group $(\mathrm{p}=0.08)$. MACE-free rate in the BITA and SITA groups were $96.6 \%$ vs. $90.2 \%, 87.4 \%$ vs. $60.6 \%$, and $70.1 \%$ vs. $51.8 \%$ at 1,3 , and 5 years, respectively. The MACE-free rate was significantly higher in the BITA group $(\mathrm{p}=0.04)$. Conclusions: While BITA grafting did not show a significant survival benefit over SITA grafting, it did not increase surgical complications and improve the MACE-free rate. BITA grafting may be a reasonable surgical strategy in dialysis-dependent patients.
\end{abstract}

\section{Introduction}

Coronary artery bypass grafting $(\mathrm{CABG})$ in patients with end-stage renal disease is often challenging due to graft selection, comorbidities, and complex perioperative management. Internal thoracic artery (ITA) grafting shows a survival benefit over saphenous vein grafting in non-dialysis ${ }^{1-5}$ and dialysis patients ${ }^{6}$. ITA grafts could be favorable for all CABG patients, because these grafts show less arteriosclerotic changes than other grafts ${ }^{3,5}$. In addition, bilateral internal thoracic artery (BITA) grafting improves long-term survival compared with single internal thoracic artery (SITA) grafting ${ }^{7-13}$. However, one recent trial showed no significant difference ${ }^{14}$. Moreover, the efficacy of BITA grafting in dialysis patients remains unclear ${ }^{15}$. We compared the short- and long-term results of BITA grafting and SITA grafting, and clarified the benefits of BITA grafting in patients with dialysis-dependent end-stage renal disease.

\section{Patients and Methods}

Dialysis-dependent end-stage renal disease patients who underwent isolated CABG during 2008-2019 were retrospectively analyzed. The study was approved by the Nagoya Heart Center Institutional Review Board approved the study. All the patients admitted to the study provided their written informed consent.

Operative Technique 
Our standard operative strategy was off-pump CABG, initially attempted without cardiopulmonary bypass. If unstable hemodynamics or uncontrolled bleeding was encountered, we inserted an intra-aortic balloon pump (IABP) or switched to on-pump beating or arrest CABG.

The ITA and right gastroepiploic artery (GEA) were harvested in a skeletonized fashion using an ultrasonic scalpel (Harmonic Scalpel; Ethicon Endo-Surgery, Cincinnati, OH). ITAs were mainly harvested by 5 experienced surgeons who had harvested over 100 ITAs.

The distribution of the graft is described in Table 1. Grafts were selected according to the coronary anatomy. Bilateral ITAs were used, except in patients with uncontrolled diabetes mellitus (DM), or those with peripheral artery disease where collateral circulation to the legs was dependent on the ITAs. During BITA grafting, the in-situ right ITA (RITA) was anastomosed to the left anterior descending artery (LAD) and the in-situ left ITA (LITA) was anastomosed to the left circumflex artery (LCx) or diagonal arteries. In some cases, the in-situ LITA was anastomosed to the LAD and the RITA was anastomosed to the LCx as a Y-composite graft with proximal anastomosis of the SVG. The LAD lesions were always revascularized with ITA. LCx lesions were revascularized with ITAs or SVGs. The right coronary artery (RCA) lesions were revascularized mainly with SVGs, except in 2 cases with GEAs and 1 case with a RITA. The GEA was used in-situ only in the presence of severe stenosis $(>90 \%)$ in young patients. Radial artery grafts were not used because all patients were on hemodialysis and had upper extremity arteriovenous grafts.

\section{Perioperative Renal Management}

The patients underwent preoperative hemodialysis based on their original schedule. Intraoperative hemodialysis was only performed for extreme electrolyte abnormality. Patients routinely underwent postoperative hemodialysis on the day of operation and the following day. On postoperative day 2, the patients resumed hemodialysis on their original schedule and their body weights were controlled in an effort to revert to their preoperative dry weight by the end of the first postoperative week. Patients with extreme postoperative weight gain were prescribed extra hemodialysis.

\section{Follow-up and Data Collection}

In-hospital mortality was defined as death for any reason during the same hospitalization. Postoperative morbidities were also recorded including rethoracotomy due to bleeding, prolonged ventilation, stroke, deep sternal wound infection (DSWI), postoperative atrial fibrillation, and fatal arrhythmia. Prolonged ventilation was defined as mechanical ventilation for over 72 hours, stroke as postoperative symptomatic and persistent neurological deficit, DSWI as surgical site infection that required antibiotics or surgical treatment, and fatal arrhythmia as ventricular fibrillation, ventricular tachycardia, or sinus arrest.

Late follow-up was performed between August 2019 and November 2019. Follow-up data were obtained from hospital charts and telephone interviews with patients, their families, and their family physicians. The two study endpoints were overall death and major adverse cardiac events (MACE) (angina; myocardial infarction; repeat revascularization; readmission for heart failure; and cardiac death, including sudden death).

\section{Statistical Analysis}

BITA and SITA groups were compared with the Fisher's exact test for categorical variables, and the MannWhitney U test for continuous variables. Overall and MACE-free survival were estimated using the KaplanMeier method. Statistical differences were analyzed using the log-rank test. Univariate and multivariate analyses of the prognostic factors of overall survival were performed using the Cox proportional hazard models. Preoperative, operative, and postoperative variables were included in the univariate analysis. Age, sex, and variables with $\mathrm{P}$ value $<0.05$ in the univariate analysis were included as variables in the multivariate analysis. $\mathrm{P}$ values $<0.05$ were considered statistically significant. All statistical analyses were performed using EZR (Saitama Medical Center, Jichi Medical University, Saitama, Japan), which is a graphical user interface for R (version 3.3.3; The R foundation for Statistical Computing, Vienna, Austria) ${ }^{16}$.

\section{Results}




\section{Patient Characteristics (Table 2)}

This study included 89 patients with dialysis-dependent end-stage renal disease (73 men and 16 women, with a mean age of $65.7 \pm 10.3$ years. In the BITA group, ejection fraction $(\mathrm{EF})<40 \%(\mathrm{p}=0.029)$ and triple vessel disease $(\mathrm{p}=0.00039)$ was more common. In the SITA group, double-vessel disease was more frequent $(\mathrm{p}=0.00019)$.

Operative Data (Table 3)

There was no significant difference in emergent cases and IABP use between the groups. Operation time $(\mathrm{p}=$ $0.0007)$ and number of distal anastomoses $(\mathrm{p}=0.0003)$ were significantly higher in the BITA group. Eightyfour patients $(94.4 \%)$ underwent off-pump CABG successfully. However, 5 patients (5.6\%) were converted to on-pump CABG for hemodynamic instability $(\mathrm{n}=3)$, for bleeding $(\mathrm{n}=1)$, and for difficulty of anastomosis because of unfavorable coronary artery anatomy $(\mathrm{n}=1)$. Incomplete revascularization was observed in 11 patients $(12.4 \%)$ due to a small coronary artery $(\mathrm{n}=8)$, chronic total occlusion of a coronary artery $(\mathrm{n}=$ $1)$, porcelain aorta $(n=1)$, and patient's preference for avoiding median sternotomy $(n=1)$. No significant differences were observed between the groups.

Early outcomes (Table 4)

The follow-up rate was $97.8 \%$ (87/89 patients). The median follow-up duration was $2.6 \pm 2.2$ years (range, 1 month to 9.9 years). There was only 1 in-hospital death overall (SITA case). There were 4 cases of rethoracotomy for postoperative bleeding, 4 cases of prolonged ventilation, 2 cases of postoperative stroke, 4 cases of DSWI, and 3 cases of fatal arrhythmia (ventricular fibrillation and ventricular tachycardia), with no significant difference between the two groups.

Late Outcomes (Table 5, 6, 7)

Cardiac death was significantly less frequent in the BITA group $(\mathrm{p}=0.003)$. There was no significant difference in the frequency of cerebral infarction and infection, or in the constituents of the MACE between the groups.

The Kaplan-Meier curves for overall and MACE-free survival are shown in Figures 1 and 2, respectively. Overall survival rates at 1,3 , and 5 years in the BITA group were $90.2 \%, 64.6 \%$, and $51.8 \%$, respectively, whereas in the SITA group, they were $82.3 \%, 57.6 \%$, and $20.6 \%$, respectively. MACE-free rates at 1,3 , and 5 years in the BITA group were $96.6 \%, 87.4 \%$, and $70.1 \%$, respectively, whereas in the SITA group were $91.5 \%$, $60.6 \%$, and $45.4 \%$, respectively. MACE-free survival rates were significantly higher in the BITA group (p $=0.04)$. Although there was no significant difference in overall survival, there was a clear tendency toward improvement in the BITA group.

Cox proportional hazard models determined the predictors of late death. Univariate analysis revealed a statistically significant correlation between late death and the following factors: age $(\mathrm{p}=0.0044)$, impaired heart function $(\mathrm{EF}<40 \%)(\mathrm{p}=0.019)$, emergent operation $(\mathrm{p}=0.018)$, incomplete revascularization $(\mathrm{p}=$ $0.0001)$, DSWI $(\mathrm{p}=0.0002)$, and postoperative stroke $(\mathrm{p}=0.008)$. Multivariate analysis revealed that age $(\mathrm{p}=0.045)$, and incomplete revascularization $(\mathrm{p}=0.002)$ were independent predictors of late death.

\section{Discussion}

This retrospective, single-center study of early and long-term results of CABG in dialysis-dependent endstage renal disease patients showed satisfactory early mortality results with no increased operative or DSWI risk with BITA grafting. The long-term results were also better in the BITA group.

BITA grafting did not increase the overall operative mortality. Our safety-focused operative strategy and postoperative management likely led to successful early results. To ensure patient safety, we minimized operative invasiveness. In patients with impaired heart function, severe left main trunk disease, or preoperative hemodynamic instability, we inserted an IABP preoperatively. We did not hesitate to insert an IABP intraoperatively or switch to on-pump surgery when patients became hemodynamically unstable during the 
operation. Moreover, we focused on postoperative fluid management and avoided postoperative intravascular dehydration to reduce the risk of non-occlusive mesenteric ischemia (NOMI). Hypovolemic shock, cardiogenic shock, and administration of alpha-adrenergic drugs were the most significant postoperative risk factors for NOMI $^{17,18}$. Patients' body weight was gradually adjusted to reach their preoperative dry weight at around the end of the first postoperative week.

Previous studies reported that BITA grafting was a risk factor for DSWI ${ }^{19-21}$, however, we found no differences in the frequency of DSWI between the groups. Our patients' ITAs were harvested by skilled surgeons using the skeletonization technique with a harmonic scalpel, which reduces the risk of DSWI ${ }^{22}$.

The long-term results showed superior MACE-free rates and less cardiac-related death in the BITA group. The BITA group showed a clear trend towards improved survival, although there was no significant difference. This might partly be because of a short follow-up period and small number of patients. Another cause might be the characteristics of dialysis patients, who are immunocompromised and exhibit accelerated atherosclerotic and arteriosclerotic changes ${ }^{23,24}$. Therefore, they are at a higher risk for non-cardiac comorbidities such as infection, stroke, and organ impairment. However, BITA grafting could have contributed to preventing cardiac-related events.

Currently, there is no consensus on the efficacy of BITA grafting in dialysis patients currently exists ${ }^{15}$. The limited number of studies on CABG in dialysis patients are mostly from Japan. BITA grafting leads to significantly fewer cardiac-related events, but not superior overall survival, when compared to SITA grafting $^{25}$. BITA grafting also may lead to reduced MACE in DM patients, although no significant difference was observed in the overall cohort ${ }^{17}$. Although most patients in our study underwent off-pump CABG, previous studies included both on-pump and off-pump procedures. This reflects changing surgical trends in Japan, where surgeons have switched from on-pump to off-pump CABG between the late 1990s and early 2000 s, during which time the off-pump technique evolved ${ }^{25,26}$. Propensity-matched analysis of off-pump CABG in hemodialysis patients was reported in 2018, which better reflected contemporary practices in Japan. Here, BITA grafting had no advantages for mid-term overall survival, freedom from cardiac death, or from cardiac events ${ }^{15}$.

BITA grafting achieved a significantly better MACE-free rate and resulted in significantly fewer cardiac deaths. Though not significantly different, the BITA group showed superior 5-year overall survival rates over those of the SITA group. This may be because GEA use (in $4.2 \%$ of patients) in the SITA group was less common than in previous reports $(22.3 \% \text { in Nakahara et al.'s study })^{15}$. Multiple arterial grafting offers some survival benefit over single arterial grafting ${ }^{27,28}$. Although we tried to use GEAs, they are often calcified and ungraftable in dialysis patients, and are prone to flow competition with the native coronary artery ${ }^{29}$. Therefore, to improve the patency of SVGs, we started no-touch harvesting in 2019, whose long-term patency is equal to ITAs ${ }^{30,31}$. Future analyses should clarify the efficacy of no-touch SVGs compared to GEA grafts.

Multivariate analysis revealed that age and incomplete revascularization significantly predicted remote death. Incomplete revascularization during off-pump CABG was an independent predictor of cardiac death, which was more pronounced in patients with impaired heart function ${ }^{32}$. In cases with difficult complete surgical revascularization, hybrid revascularization involving CABG and percutaneous coronary intervention should be considered to minimize perioperative risk and prevent remote cardiac death.

There are several limitations to this study. First, this was a single-center, non-randomized, retrospective, and observational study. Second, the number of patients was relatively small; no definitive conclusions could be reached. Third, the follow-up period was relatively short.

\section{Conclusion}

CABG using BITA grafting in hemodialysis patients is a promising approach for improving long-term prognosis. Further efforts to improve long-term survival in patients undergoing SITA grafting are needed.

Conflicts of Interest: none 


\section{Author Contributions:}

Concept/design: YK, HK, MT, YO

Data analysis/interpretation: YK, HK, MT

Drafting Article: YK, HK

Critical revision of article: YU, HK, MT, YO

Approval of article: All authors

Statistics: YK, KK, HK

Data collection: YK, KK

\section{References}

1. Zeff RH, Kongtahworn C, Iannone LA, et al. Internal mammary artery versus saphenous vein graft to the left anterior descending coronary artery: Prospective randomized study with 10-year follow-up. Ann Thorac Surg 1988;45:533-536.

2. Loop FD, Lytle BW, Cosgrove DM, et al. Influence of the internal-mammary-artery graft on 10-year survival and other cardiac events. N Engl J Med 1986;314:1-6.

3. Cameron A, Davis KB, Green G, Schaff HV. Coronary bypass surgery with internal-thoracic-artery grafts — effects on survival over a 15-year period. N Engl J Med 1996;334:216-219.

4. Grondin CM, Campeau L, Lesperance J, Enjalbert M, Bourassa MG. Comparison of late changes in internal mammary artery and saphenous vein grafts in two consecutive series of patients 10 years after operation. Circulation 1984;70:I208-212.

5. Sabik JF 3rd, Lytle BW, Blackstone EH, Houghtaling PL, Cosgrove DM. Comparison of saphenous vein and internal thoracic artery graft patency by coronary system. Ann Thorac Surg 2005;79:544-551.

6. Shilane D, Hlatky MA, Winkelmayer WC, Chang TI. Coronary artery bypass graft type and outcomes in maintenance dialysis. J Cardiovasc Surg (Torino) 2015;56:463-471

7. Lytle BW, Blackstone EH, Sabik JF, Houghtailing P, Loop FD, Cosgrove DM. The effect of bilateral internal thoracic artery grafting on survival during 20 postoperative years. Ann Thorac Surg 2004;78:20052014 .

8. Kurlansky PA, Traad EA, Dorman MJ, Galbut DL, Zucker M, Ebra G. Thirty-year follow-up defines survival benefit for second internal mammary artery in propensity-matched groups. Ann Thorac Surg 2010;90:101108.

9. Kieser TM, Lewin AM, Graham MM, et al. Outcomes associated with bilateral internal thoracic artery grafting: the importance of age. Ann Thorac Surg 2011;92:1269-1276.

10. Grau JB, Ferrari G, Mac AW, et al. Propensity matched analysis of bilateral internal mammary artery versus single left internal mammary artery grafting at 17-year follow-up: validation of a contemporary surgical experience. Eur J Cardiothorac Surg 2012;41:770-775.

11. Galbut DL, Kulansky PA, Traad EA, Dorman MJ, Zucker M, Ebra J. Bilateral internal thoracic artery grafting improves long-term survival in patients with reduced ejection fraction; A propensity-matched study with 30-year follow-up. J Thorac Cardiovasc Surg 2012;143:844-853.

12. Locker C, Schaff HV, Dearani JA, et al. Multiple arterial grafts improve late survival of patients undergoing coronary artery bypass graft surgery: analysis of 8622 patients with multivessel disease. Circulation 2012;126:1023-1030. 
13. Smith T, Kloppenburg GT, Morshuis WJ. Does the use of bilateral mammary artery grafts compared with the use of a single mammary artery graft offer a long-term survival benefit in patients undergoing coronary artery bypass surgery? Interact Cardiovasc Thorac Surg 2014;18:96-101

14. Taggart DP, Benedetto U, Gerry S, et al. Bilateral versus single internal thoracic artery grafts at 10 years. N Engl J Med 2019;380:437-446

15. Nakahara Y, Yoshida S, Kanemura T, Yamagishi S, Tochigh S, Osaka S. Bilateral internal thoracic artery grafts in hemodialysis: A single-center propensity score analysis. Ann Thorac Surg 2018;105:153-159

16. Kanda Y. Investigation of the freely-available easy-to-use software "EZR" (Easy R) for medical statistics. Bone Marrow Transplant 2013;48:452-458.

17. Lock G. Acute intestinal ischemia. Best Pract Res Clin Gastroenterol 2001;15:83-98.

18. Trompeter M, Brazda T, Remy CT, Vestring T, Reimer P. Non-occlusive mesenteric ischemia: etiology, diagnosis, and interventional therapy. Eur Radiol 2002;12:1179-1187.

19. Nakano J, Okabayashi H, Hanyu M, et al. Risk factors for wound infection after off-pump coronary artery bypass grafting: Should bilateral internal thoracic arteries be harvested in patients with diabetes? J Thorac Cardiovasc Surg 2008;135:540-545.

20. Dai C, Lu Z, Zhu H, Xue S, Lian F. Bilateral internal mammary artery grafting and risk of sternal wound infection: Evidence from observational studies. Ann Thorac Surg 2013;95:1938-1945.

21. Kieser TM, Rose MS, Aluthman U, Montgomery M, Louie T, Belenkie I. Toward zero: Deep sternal wound infection after 1001 consecutive coronary artery bypass procedures using arterial grafts: implications for diabetic patients. J Thorac Cardiovasc Surg 2014;148:1887-1895.

22. Ngu JMC, Guo MH, Glineur D, Tran D, Rubens FD. The balance between short-term and long-term outcomes of bilateral internal thoracic artery skeletonization in coronary artery bypass surgery: a propensitymatched cohort study. Eur J Cardiothorac Surg 2018;54:260-266

23. Kato S. Chmielewski M, Honda H, et al. Aspects of immune dysfunction in end-stage renal disease. Clin J Am Soc Nephrol 2008;3:1526-1533.

24. Chirakarnjanakorn S, Navaneethan SD, Francis GS, Tang WH. Cardiovascular impact in patients undergoing maintenance hemodialysis: clinical management considerations. Int J Cardiol 2017;232:12-23.

25. Kai M, Okabayashi H, Hanyu M, et al. Long-term results of bilateral internal thoracic artery grafting in dialysis patients. Ann Thoracic Surg 2007;83:1666-1671.

26. Nakatsu T, Tamura N, Sakakibara Y, Hagio Y, Ishigami M. Long-term survival after coronary arterial grafts in patients with end-stage renal disease. Ann Thorac Surg 2010;90:738-743.

27. Glineur D, D'hoore W, Price J, et al. Survival benefit of multiple arterial grafting in a 25-year single institutional experience: the importance of the third arterial graft. Eur J Cardiothorac Surg 2012;42:284-291.

28. Suzuki T, Asai T, Matsubayashi K, et al. In off-pump surgery, skeletonized gastroepiploic artery is superior to saphenous vein in patients with bilateral internal thoracic arterial grafts. Ann Thorac Surg 2011;91:1159-1164.

29. Glineur D, Hanet C, Poncelet A, et al. Comparison of saphenous vein graft versus right gastroepiploic artery to revascularize the right coronary artery: a prospective randomized clinical, functional, and angiographic midterm evaluation. J Thorac Cardiovasc Surg 2008;136:482-488.

30. Souza D. A new no-touch preparation technique. Technical notes. Scand J Thorac Cardiovasc Surg 1996;30:41-44. 
31. Samano N, Geijer H, Liden M, Fremes S, Bodin L, Souza D. The no-touch saphenous vein for coronary artery bypass grafting maintains a patency, after 16 years, comparable to the left internal thoracic artery; A randomized trial. J Thorac Cardiovasc Surg 2015;150:880-888.

32. Yi G, Youn YN, Joo HC, Hong S, Yoo KJ. Association of incomplete revascularization with long-term survival after off-pump coronary artery bypass grafting. J Surg Res 2013;185:166-173.

Tables

\begin{tabular}{lll}
\hline Table 1: Distribution of the grafts & Table 1: Distribution of the grafts & Table 1: Distribution of the grafts \\
\hline BITA $(\mathrm{n}=65)$ & LITA $(\mathrm{n}=65)$ & RITA $(\mathrm{n}=65)$ \\
LAD & $20(30.8)$ & $56(86.2)$ \\
Cx & $51(78.5)$ & $10(15.4)$ \\
RCA $(\mathrm{n}=24)$ & 0 & $1(1.5)$ \\
SITA & RITA $(\mathrm{n}=3)$ \\
LAD & LITA $(\mathrm{n}=21)$ & $3(100.0)$ \\
Cx & $21(100.0)$ & 0 \\
RCA & 0 & 0 \\
\hline
\end{tabular}

Values are presented as number $(\%)$

BITA, bilateral internal thoracic artery; GEA, gastroepiploic artery; LAD, left anterior descending artery; LCx, left circumflex artery; LITA, left internal thoracic artery; RCA, right coronary artery; RITA, right internal thoracic artery; SITA, single internal thoracic artery; SVG, saphenous vein graft

\begin{tabular}{|c|c|c|c|}
\hline Table 2: Patient characteristics & Table 2: Patient characteristics & Table 2: Patient characteristics & Table : \\
\hline Characteristics & All $(\mathrm{n}=89)$ & SITA $(\mathrm{n}=24)$ & BITA ( \\
\hline Age, years & $65.7 \pm 10.3$ & $67.9 \pm 11.4$ & $65.0 \pm$ \\
\hline Male & $73(82.0)$ & $18(75.0)$ & $55(84.6$ \\
\hline BMI, $\mathrm{kg} / \mathrm{m}^{2}$ & $23.2 \pm 4.0$ & $23.1 \pm 3.5$ & $23.3 \pm$ \\
\hline Hypertension & $53(59.6)$ & $16(66.7)$ & $37(56.9$ \\
\hline Hyperlipidemia & $48(53.9)$ & $9(37.5)$ & $39(60.0$ \\
\hline Diabetes millitus & $60(67.4)$ & $16(66.7)$ & $44(67.7)$ \\
\hline Insulin use & $14(15.7)$ & $2(8.3)$ & $12(18.5$ \\
\hline Cerebral infarction & $11(12.4)$ & $1(4.2)$ & $10(15.4$ \\
\hline $\mathrm{PAD}$ & $25(28.1)$ & $9(37.5)$ & $16(24.6$ \\
\hline COPD & $30(33.7)$ & $7(29.2)$ & $23(35.4$ \\
\hline Hemodialysis duration, years & $8.3 \pm 8.2$ & $6.7 \pm 5.0$ & $8.9 \pm 9$ \\
\hline Etiology of dialysis induction & Etiology of dialysis induction & & \\
\hline Diabetes mellitus & $60(67.4)$ & $16(66.7)$ & $44(67.7$ \\
\hline Glomerulonephritis & $18(20.2)$ & $5(20.8)$ & $13(20.0$ \\
\hline Nephrosclerosis & $5(5.6)$ & $2(8.3)$ & $3(4.6)$ \\
\hline Unknown, others & $6(6.7)$ & $1(4.2)$ & $5(7.7)$ \\
\hline Atrial fibrillation & $5(5.6)$ & 0 & $5(7.7)$ \\
\hline $\mathrm{LVEF}<40 \%$ & $36(40.4)$ & $5(20.8)$ & $31(47.7$ \\
\hline LVDd $>50 \mathrm{~mm}$ & $49(55.1)$ & $14(58.3)$ & $35(53.8$ \\
\hline OMI & $22(24.7)$ & $4(16.7)$ & $18(27.7$ \\
\hline Previous PCI & $32(36.0)$ & $9(37.5)$ & $23(35.4$ \\
\hline Aortic stenosis & $11(12.4)$ & $4(16.7)$ & $7(10.8)$ \\
\hline trivial-mild & $9(10.1)$ & $3(12.5)$ & $6(9.2)$ \\
\hline moderate & $2(2.2)$ & $1(4.2)$ & $1(1.5)$ \\
\hline
\end{tabular}




\begin{tabular}{llll}
\hline Table 2: Patient characteristics & Table 2: Patient characteristics & Table 2: Patient characteristics & Table \\
\hline Mitral regurgitation & $78(87.6)$ & $22(91.7)$ & $56(86.2$ \\
trivial-mild & $69(77.5)$ & $19(21.3)$ & $50(56.2$ \\
moderate & $9(10.1)$ & $3(12.5)$ & $6(6.7)$ \\
Coronary artery disease & Coronary artery disease & $5(20.8)$ & $16(24.6$ \\
LMT disease & $21(23.6)$ & $12(50.0)$ & $57(87.7$ \\
Triple-vessel disease & $69(77.5)$ & $11(45.8)$ & $7(10.8)$ \\
Double-vessel disease & $18(20.2)$ & $1(4.2)$ & 0 \\
Single-vessel disease & $1(11.2)$ & & \\
\hline
\end{tabular}

Values are presented as number (\%) or mean \pm standard deviation

COPD, chronic obstructive pulmonary disease; LMT, left main trunk; LVDd, left ventricle diastolic dimension; LVEF, left ventricle ejection fraction; OMI, old myocardial infarction; PAD, peripheral artery disease; PCI, percutaneous coronary intervention

\begin{tabular}{llll}
\hline Table 3: Operative results & Table 3: Operative results & Table 3: Operative results & Table 3: Operative re \\
\hline Characteristics & All $(\mathrm{n}=89)$ & SITA $(\mathrm{n}=24)$ & BITA $(\mathrm{n}=65)$ \\
Emergent operation & $8(9.0)$ & $2(8.3)$ & $6(9.2)$ \\
IABP use & $12(13.5)$ & $2(8.3)$ & $10(15.4)$ \\
Operation time, min & $262.3 \pm 69.1$ & $222.6 \pm 64.0$ & $276.9 \pm 65.4$ \\
No of anastomosis & $3.27 \pm 1.13$ & $2.58 \pm 1.06$ & $3.52 \pm 1.05$ \\
Conversion & $5(5.6)$ & $2(8.3)$ & $3(4.6)$ \\
Incomplete revascularization & $11(12.4)$ & $6(25.0)$ & $5(7.7)$ \\
\hline
\end{tabular}

Values are presented as number (\%) or mean \pm standard deviation

BITA, bilateral internal thoracic artery; IABP, intra-aortic balloon pumping; SITA, single internal thoracic artery

\begin{tabular}{llll}
\hline Table 4: Early outcomes & Table 4: Early outcomes & Table 4: Early outcomes & Table 4: Early outcomes \\
\hline Variable & All $(\mathrm{n}=89)$ & SITA $(\mathrm{n}=24)$ & BITA $(\mathrm{n}=65)$ \\
Inhospital death & $1(1.1)$ & $1(4.2)$ & 0 \\
Comorbidities & & & \\
Rethoracotomy & $4(4.5)$ & $1(4.2)$ & $3(4.6)$ \\
Prolonged ventilation & $4(4.5)$ & $1(4.2)$ & $3(4.6)$ \\
Stroke & $2(2.2)$ & $1(4.2)$ & $1(1.5)$ \\
DSWI & $4(4.5)$ & $1(4.2)$ & $3(4.6)$ \\
POAF & $19(21.3)$ & $4(16.7)$ & $15(23.1)$ \\
Fatal arrhythmia & $3(3.4)$ & 0 & $3(4.6)$ \\
Follow-up period, years & $2.6 \pm 2.2$ & $2.1 \pm 1.9$ & $2.8 \pm 2.3$ \\
\hline
\end{tabular}

Values are presented as number (\%) or mean \pm standard deviation

BITA, bilateral internal thoracic artery; DSWI, deep surgical wound infection; POAF, postoperative atrial fibrillation; SITA, single internal thoracic artery 
Table 5: Causes of late death and major adverse cardiac events

All death
cardiac death
cerebral infarction
infection
intestinal necrosis
cancer
other
MACE
sudden death, fatal arrhythmia
repeat revascularization
heart failure

Table 5: Causes of late death and major a

All $(\mathrm{n}=89)$

$35(39.3)$

$10(11.2)$

$2(2.2)$

$8(9.0)$

$2(2.2)$

$3(3.4)$

$10(11.2)$

$16(18.0)$

$8(9.0)$

$7(7.9)$

$1(1.1)$

Values are presented as number (\%)

BITA, bilateral internal thoracic artery; MACE, major adverse cardiac event; SITA, single internal thoracic artery

Table 6: Univariate analysis of factors associated with all-cause death Table 6: Univariate analysis of fact

Preoperative variables

Age HR

Sex

1.05

Hypertension

0.48

Hyperlipidemia

0.85

Diabetes mellitus

0.75

Cerebral infarction

1.76

PAD

1.18

COPD

1.81

1.23

Hemodialysis duration $\quad 1.01$

Atrial fibrillation $\quad 1.86$

$\begin{array}{ll}\text { LVEF }<40 \% & 2.24\end{array}$

$\begin{array}{ll}\text { LVDd }>50 \mathrm{~mm} & 1.7\end{array}$

$\begin{array}{ll}\text { OMI } & 1.09\end{array}$

$\begin{array}{ll}\text { Previous PCI } & 0.84\end{array}$

MR > moderate $\quad 1.44$

$\begin{array}{ll}\text { Triple-vessel disease } & 0.79\end{array}$

$\begin{array}{ll}\text { Left main trunk disease } & 1.37\end{array}$

Operative variables

$\begin{array}{ll}\text { Emergent case } & 3.02\end{array}$

IABP use $\quad 1.82$

$\begin{array}{ll}\text { Incomplete revascularization } & 4.19\end{array}$

ITA side anastomosed to LAD $\quad 1.64$

Off-pump surgery $r .42$

$\begin{array}{ll}\text { BITA grafting } & 0.54\end{array}$

$\begin{array}{ll}\text { Postoperative variables } & 1.7 \\ \text { POAF } & 13\end{array}$

$\begin{array}{ll}\text { DSWI } & 13\end{array}$

$\begin{array}{ll}\text { Prolonged ventilation } & 1.73\end{array}$ 
Table 6: Univariate analysis of factors associated with all-cause death

Table 6: Univariate analysis of fact

Rethoracotomy

1.74

Stroke

7.76

BITA, bilateral internal thoracic artery; COPD, chronic obstructive pulmonary disease; DSWI, deep surgical wound infection; HR, hazards ratio; IABP, intraaortic balloon pumping; ITA, internal thoracic artery; LAD, left anterior descending artery; LVDd, left ventricle diastolic dimension; LVEF, left ventricle ejection fraction; MR, mitral regurgitation; OMI, old myocardial infarction; PAD, peripheral artery disease; PCI, percutaneous catheter intervention; POAF, postoperative atrial fibrillation

\begin{tabular}{ll}
\hline Table 7: Multivariate analysis of factors associated with all-cause death & Table 7: Multivariate analysis of \\
\hline & $\mathrm{HR}$ \\
Age & 1.04 \\
Male & 0.70 \\
LVEF $<40 \%$ & 1.79 \\
Emergent case & 1.42 \\
Incomplete revascularization & 3.38 \\
DSWI & 3.47 \\
Stroke & 3.32 \\
\hline
\end{tabular}

DSWI, deep surgical wound infection; HR, hazards ratio; LVEF, left ventricle ejection fraction

\section{Figure Legends}

Figure 1. Kaplan-Meier analysis of the overall survival

BITA, bilateral internal thoracic artery; SITA, single internal thoracic artery

Figure 2. Kaplan-Meier analysis of freedom from major adverse cardiac events

BITA, bilateral internal thoracic artery; MACE, major adverse cardiac events; SITA, single internal thoracic artery 

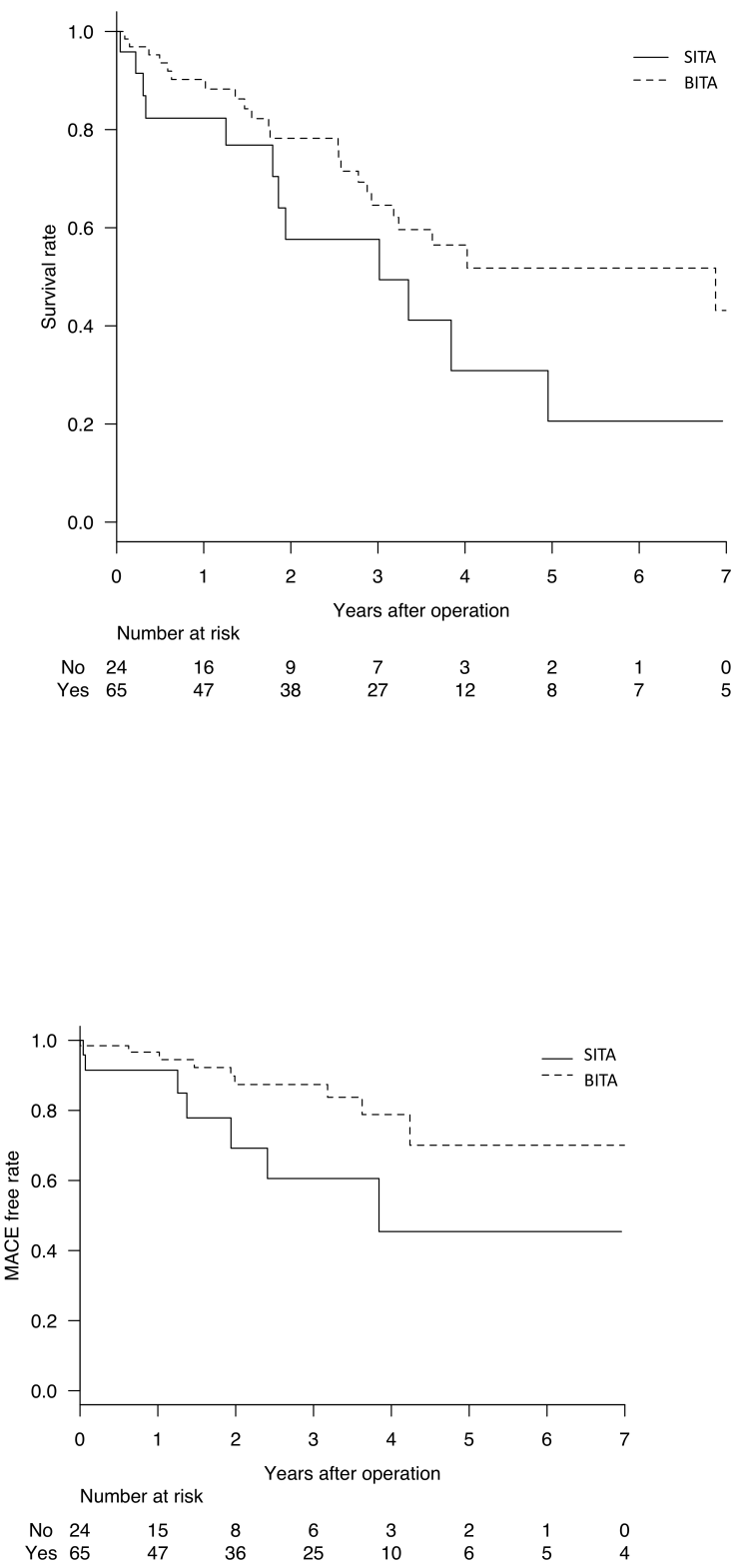